the authors and not necessarily those of the NHS, the National Institute for Health Research, the Department of Health or the MRC.

\section{Competing interests None.}

Contributors Dr Samantha Kon and Dr Man both reviewed the accompanying manuscript. Dr Kon wrote the first draft of the editorial and agreed to the final version. Dr Man takes responsibility for the accuracy and views of the final version of the editorial.

Provenance and peer review Commissioned internally peer reviewed.

Published Online First 3 August 201

Thorax 2011:66:933-935

doi:10.1136/thoraxjnl-2011-200774

\section{REFERENCES}

1. Lacasse $\mathbf{Y}$, Goldstein R, Lasserson TJ, et al. Pulmonary rehabilitation for chronic obstructive pulmonary disease. Cochrane Database Syst Rev 2006;(4):CD003793.

2. Swallow EB, Reyes D, Hopkinson NS, et al. Quadriceps strength predicts mortality in patients with moderate to severe chronic obstructive pulmonary disease. Thorax 2007;62:115-20.

3. Williams TJ, Patterson GA, McClean PA, et al. Maximal exercise testing in single and double lung transplant recipients. Am Rev Respir Dis 1992;145:101-5.

4. Man WD, Soliman MG, Gearing J, et al. Symptoms and quadriceps fatigability after walking and cycling in chronic obstructive pulmonary disease. $A m \mathrm{~J}$ Respir Crit Care Med 2003;168:562-7.

5. Man WD, Soliman MG, Nikoletou D, et al. Nonvolitional assessment of skeletal muscle strength in patients with chronic obstructive pulmonary disease. Thorax 2003:58:665-9.

6. Swallow EB, Gosker HR, Ward KA, et al. A novel technique for nonvolitional assessment of quadriceps muscle endurance in humans. J Appl Physiol 2007; 103:739-46.

7. Man WD, Kemp P, Moxham J, et al. Skeletal muscle dysfunction in COPD: clinical and laboratory observations. Clin Sci (Lond) 2009;117:251-64.

8. Simpson K, Killian K, McCartney N, et al. Randomised controlled trial of weightlifting exercise in patients with chronic aifflow limitation. Thorax 1992:47:70-5.

9. Decramer M, Gosselink R, Troosters T, et al. Muscle weakness is related to utilization of health care resources in COPD patients. Eur Respir $\mathrm{J}$ 1997:10:417-23.

10. Marquis K, Debigare $R$, Lacasse $Y$, et al. Midthigh muscle cross-sectional area is a better predictor of mortality than body mass index in patients with chronic obstructive pulmonary disease. Am J Respir Crit Care Med 2002;166:809-13.

11. van den Borst B, Koster $A, Y u B$, et al; For the Health $A B C$ Study. Is age-related decline in lean mass and physical function accelerated by obstructive lung disease or smoking? Thorax 2011;66:961-9

12. Cawthon PM, Marshall LM, Michael Y, et al. Frailty in older men: prevalence, progression, and relationship with mortality. J Am Geriatr Soc 2007:55:1216-23.

13. Nakatani T, Nakashima T, Kita T, et al. Responses of exposure to cigarette smoke at three dosage levels on soleus muscle fibers in Wistar-Kyoto and spontaneously hypertensive rats. Jpn J Pharmacol 2002;90:157-63.

14. Nakatani T, Nakashima T, Kita T, et al. Effects of exposure to cigarette smoke at different dose levels on extensor digitorum longus muscle fibres in Wistar-Kyoto and spontaneously hypertensive rats. Clin Exp Pharmacol Physiol 2003;30:671-7.

15. Wust RC, Morse $\mathrm{Cl}$, de Haan $\mathrm{A}$, et al. Skeletal muscle properties and fatigue resistance in relation to smoking history. Eur J Appl Physiol

2008;104:103-10.

16. Montes de Oca M, Loeb E, Torres SH, et al. Peripheral muscle alterations in non-COPD smokers. Chest 2008;133:13-18.

17. Seymour JM, Spruit MA, Hopkinson NS, et al. The prevalence of quadriceps weakness in COPD and the relationship with disease severity. Eur Respir $J$ 2010;36:81-88

18. Kaczynski AT, Manske SR, Mannell RC, et al. Smoking and physical activity: a systematic review. Am J Health Behav 2008;32:93-110.

19. Watz H, Waschki B, Boehme C, et al. Extrapulmonary effects of chronic obstructive pulmonary disease on physical activity: a cross-sectional study. Am J Respir Crit Care Med 2008;177:743-51

20. Man WD, Grant A, Hogg L, et al. Pulmonary rehabilitation in patients with MRC Dyspnoea Scale 2 Thorax 2011:66:263.

\title{
Action plans for COPD self- management. Integrated care is more than the sum of its parts
}

\section{D L Morgan}

The past few years have seen significant changes in attitude in many countries towards the care of people with chronic obstructive pulmonary disease (COPD). These changes have been driven by a greater understanding of the disease and the nature of its impact. Although there have been no new therapies that can modify the course of airway obstruction, there have been considerable advances in the way that we can lessen the impact of the disease on both the patient and the health community. There has clearly been a desire to improve the lives of individual people with COPD, but the major catalyst for change has probably been the desire of

Correspondence to Professor M D L Morgan, Department of Respiratory Medicine University Hospitals of Leicester, Glenfield Hospital, Leicester LE3 90P, UK; mike.morgan@uhl-tr.nhs.uk commissioners to reduce the cost of unnecessary hospital admissions resulting from exacerbation. To this end, the development of admission avoidance schemes has stimulated integrated community care programmes and importantly the involvement of the patient through a process known as self-management. The constituents of published selfmanagement programmes vary quite widely, but most contain an action plan in the form of a set of instructions to inform the patient how to recognise an exacerbation and act accordingly. This is usually presented in a written format but can be pictorial if there are language difficulties or literacy issues. ${ }^{1}$ If they are also armed with treatment in the form of steroids and antibiotics, then it would be hoped that prompt action by the patient would then attenuate the serious exacerbation that would otherwise result in a hospital admission. The article by Trappenburg ${ }^{2}$ in this month's journal sheds further light on the individual effectiveness of the action plan on the outcome of acute exacerbations of COPD.

In spite of the fact that early treatment may improve the outcome of exacerbations, the introduction of stand-alone action plans and access to medication for patient-initiated use has been largely disappointing. ${ }^{3}$ The data from the most recent systematic review covering five trials indicate that although they increase recognition and steroid/antibiotic use, they have no impact on the use of healthcare resources. In particular, no reduction in hospital admissions, emergency department visits or GP attendances was evident. ${ }^{4}$ It seems that people with action plans recognise exacerbations and take more therapy without affecting the outcome. This does not seem to make a lot of sense when you appreciate that they will get essentially the same treatment when they do end up in the hospital. This year, two papers in Thorax have shed some light on this puzzle. In the first paper, Bischoff et al ${ }^{5}$ explored the effect of adherence to written action plans on the recovery from exacerbation in 143 patients who had 288 exacerbations. The written plan was only followed in $40 \%$ of the exacerbations, but where patients 
complied with the instructions, the rate of recovery was faster but still had no impact on healthcare use. The other study in this month's issue by Trappenburg and others from Canada and the Netherlands examined the impact of written action plans on exacerbation duration and the recovery of health status reflected by the Clinical COPD Questionnaire. In this case, the inspection of a more subtle outcome such as health status seems to demonstrate a benefit. Nevertheless, even in this substantial randomised study, there was no reduction in exacerbation frequency or healthcare use. Furthermore, this trial is slightly compromised by the addition of ongoing telephone support from a case manager in the active group that may have added some benefit. So what are we to learn? It is tempting to conclude that simply giving patients a written action plan for exacerbations offers no useful advantage. This conclusion may be true but actually misses the point because the successful management of COPD is more than the sum of its parts.

The recent shift in attitude surrounding chronic disease management in recent years has followed the recognition that in the absence of disease-modifying therapy, the old reactive response to disease progression has proved unsuccessful. A more progressive response is to follow the lead of other chronic diseases and apply the principles of the chronic care model (CCM) to COPD. ${ }^{6}$ The guiding principle of the CCM is a collaborative interaction between an informed patient and knowledgeable healthcare professionals who have a series of supportive components to assist them. These components include self-management education for the patient, delivery system design, decision support guidelines and a clinical information system that will facilitate a registration and review process. Ideally, these components are delivered at a practical level by an integrated service that crosses the boundaries of primary and secondary care and includes the elements of diagnosis and review, self-management education and rehabilitation, oxygen assessment and a community system for dealing with exacerbations. We know that when at least two components of the CCM are included, then they do have a beneficial effect on healthcare use in terms of a reduction in hospital admissions and shorter lengths of stay. ${ }^{7}$ Recent local or even national programmed management along these lines has shown large reductions in hospital admissions of up to $40 \%{ }^{89}$

If we acknowledge that the whole system of integrated care that adheres to the CCM is capable of producing reductions in hospital admissions, then why are action plans alone relatively ineffective? Well, the answer seems to lie in how the action plan is delivered to the patient. The self-treatment of exacerbations is a responsibility for the patient who is already well versed in self-management education. Patients have to learn how to recognise an exacerbation before taking action, and that experience may have specific features for each individual. ${ }^{10}$ So, you may imagine that an action plan will only work or be adhered to if it is delivered in the context of more extensive, individualised, self-management education. That seems to be the case in a recent study by Effing et $a l^{11}$ who investigated what happens if self-treatment advice is excluded from self-management education programmes. They discovered that patients who received self-management and self-treatment advice had fewer exacerbation days and a reduction in healthcare contacts resulting in a positive cost-benefit saving. So, if action plans for self-treatment are only effective if they are delivered within a programme of selfmanagement education, then we should be clear about what constitutes selfmanagement. Can we simply give patients a few leaflets and an action plan and expect them to get on with it? Well, this approach, although it might appeal to cash-strapped commissioners, does not follow the principles of collaborative self-management envisaged in the CCM. The intention of the process is that it changes behaviour and instils the confidence to recognise exacerbations and take responsibility. ${ }^{12}$ This is a much broader ambition than simply avoiding hospital admission, although it may do so as a consequence. The other important principle of continuing effective selfmanagement is that it receives ongoing support by the health professional. The economically successful disease management programmes have all had ongoing case manager support available to a patient if they feel that they need it. This potential for contact with a member of the expert team will bolster the patient's confidence to self-manage and self-treat.
Action plans for exacerbations are probably a vital part of collaborative and supported self-management. Using them in isolation, however, is unlikely to be effective. The arguments for following the principles of the CCM and integrated care are now very strong, but they may be less effective if the individual components are not joined up. We should be pressing commissioners to look at the whole pathway of care for COPD and not be tempted to purchase individual services where they do not combine to a synthesis that is more than the sum of its parts.

\section{Competing interests None.}

Provenance and peer review Commissioned; internally peer reviewed.

Published Online First 3 August 2011

Thorax 2011;66:935-936.

doi:10.1136/thoraxjnl-2011-200783

\section{REFERENCES}

1. Roberts NJ, Partridge MR. Evaluation of a paper and electronic pictorial COPD action plan. Chron Respir Dis 2011;8:31-40.

2. Trappenburg JCA, Monninkhof EM, Bourbeau J, et al. Effect of an action plan with ongoing support by a case manager on exacerbation-related outcome in patients with COPD: a multicentre randomised controlled trial. Thorax 2011;66:977-84.

3. Wilkinson TM, Donaldson GC, Hurst JR, et al. Early therapy improves outcomes of exacerbations of chronic obstructive pulmonary disease. Am J Respir Crit Care Med 2004;169:1298-303.

4. Walters JA, Turnock AC, Walters EH, et al. Action plans with limited patient education only for exacerbations of chronic obstructive pulmonary disease. Cochrane Database Syst Rev 2010;(5): CD005074.

5. Bischoff EW, Hamd DH, Sedeno M, et al. Effects of written action plan adherence on COPD exacerbation recovery. Thorax 2011;66:26-31.

6. Wagner EH, Austin BT, Von Korff M. Improving outcomes in chronic illness. Manag Care 0 1996;4:12-25.

7. Adams SG, Smith PK, Allan PF, et al. Systematic review of the chronic care model in chronic obstructive pulmonary disease prevention and management. Arch Intern Med 2007;167:551-61

8. Rice KL, Dewan N, Bloomfield HE, et al. Disease management program for chronic obstructive pulmonary disease: a randomized controlled trial. $A m$ J Respir Crit Care Med 2010;182:890-6.

9. Kinnula VL, Vasankari T, Kontula E, et al. The 10year COPD Programme in Finland: effects on quality of diagnosis, smoking, prevalence, hospital admissions and mortality. Prim Care Respir J 2011;20:178-83

10. Costi S, Brooks D, Goldstein RS. Perspectives that influence action plans for chronic obstructive pulmonary disease. Can Respir J 2006:13:362-8.

11. Effing $\mathbf{T}$, Kerstjens $H$, van der Valk $P$, et al. (Cost)effectiveness of self-treatment of exacerbations on the severity of exacerbations in patients with COPD: the COPE II study. Thorax 2009;64:956-62.

12. Bourbeau J. The role of collaborative selfmanagement in pulmonary rehabilitation. Semin Respir Crit Care Med 2009:30:700-7. 